\title{
Association between anxiety and sleep quality in the general surgery residents of Udayana University
}

\author{
Ida Bagus Gede Wisnu Wardhana, \\ Cokorda Bagus Jaya Lesmana, \\ Luh Nyoman Alit Aryani, \\ Wayan Westa, \\ I Gusti Ayu Endah Ardjana, \\ Ni Ketut Sri Diniari
}

Department of Psychiatry, Faculty of Medicine Udayana University/Sanglah General Hospital Bali, Indonesia

\section{Cite this article:}

Wardhana IBGW, Lesmana CBJ, Aryani LNA, Westa W,Ardjana IGAE, Diniari NKS.Association Between Anxiety and Sleep Quality in The General Surgery Residents of Udayana University. Journal of Clinical and Cultural Psychiatry. 2020; I (I): 5-8.

Corresponding author:

Cokorda Bagus Jaya Lesmana

Department of Psychiatry, Faculty of Medicine Udayana University/Sanglah General Hospital Jl. Kesehatan No I, Bali 80I I4, Indonesia cokordabagus@unud.ac.id

\begin{abstract}
Background: Sleep quality not only affects physical health but also on individual performance. Anxiety is thought to associate with poor sleep quality. This study aims to determine the association between anxiety and sleep quality in surgery residents of Faculty of Medicine, Udayana University.

Methods: The subjects of the study were 48 surgery residents of Faculty of Medicine of Udayana University. The study used a cross sectional analytical method. Measurement of anxiety using the Beck Anxiety Inventory (BAI) and sleep quality questionnaire using the Pittsburgh Sleep Quality Index (PSQI). Data were analyzed descriptively and used the chi square test with significance level $\mathrm{p}<0.05$.

Results: The results showed that $33.3 \%$ of surgery residents of Faculty of Medicine of Udayana University had anxiety and most had poor sleep quality ( $87.5 \%)$. There is an association between anxiety and sleep quality in surgery residents of Faculty of Medicine of Udayana University with PR 3.0 (95\% CI 0,9-9,1; p <0.005).

Conclusion: This study shows that there is a significant relationship between anxiety and sleep quality where surgery residents of Faculty of Medicine of Udayana University with anxiety 3 times at risk of developing poor sleep quality than those without anxiety. Therefore it is necessary to manage anxiety as well as the arrangement of night shift to improve sleep quality.
\end{abstract}

Keywords: anxiety, sleep quality, surgery resident, BAI, PSQI

\section{Introduction}

Anxiety is a negative emotional state characterized by somatic disorders, such as heart beating fast, sweating, difficulty breathing. Anxiety is similar to fear but with a less specific focus. Anxiety is characterized by concerns about the unexpected danger that lies in the future, while fear is a response to an immediate threat. ${ }^{1}$

Anxiety disorder is one of the mental disorders that often occurs in societies with a worldwide prevalence of $2.5-7 \%$ in each country. ${ }^{2}$ An estimated 284 million people worldwide experience anxiety disorders in 2017.3 Anxiety affects sleep quality. ${ }^{4}$ The relationship of anxiety and sleep disorders is important to know because overcoming anxiety will improve sleep quality. Sleep is a physiological need for humans. Poor sleep and poor quality can cause impaired physiological and psychological balance. ${ }^{1}$

Sleep disorder is disorder that often occurs but are often ignored. Sleep disorders will affect one's health status, morbidity, and are associated with increased mortality. ${ }^{5}$ Physiological and psychological effects that arise due to poor sleep quality include decreased daily activity, fatigue, impaired motor response, decreased endurance, stress, depression and anxiety. Lack of sleep 
can result in social disturbances, performance, learning achievement, mental health, and other functions. ${ }^{6}$

General Surgery residents at Sanglah General Hospital often have to deal with tiring and unexpected schedules, financial challenges, as well as difficult emotional problems, high levels of stressors, and very potentially cause anxiety. Especially doctors participating in surgical specialist education programs. This anxiety can cause sleep quality disorders. Side effects of disruption of sleep quality, namely: drowsiness, reduced alertness, impaired concentration of attention, impaired cognitive function to perform complex functions, and impaired executive function so that it will affect the academic ability of students.

This study aims to determine the relationship between anxiety and sleep quality among the General Surgery residents of Udayana University.

\section{Methods}

This was an observational, analytic, cross-sectional study, using randomized sampling. The subjects were the General Surgery residents of Sanglah General Hospital. The study protocol was approved by the institutional review board of Sanglah General Hospital.

The inclusion criteria were General Surgery residents who were willing to be included in this study by signing a written informed consent. The exclusion criteria were the ones who were undergoing physical and mental pain therapy.

Anxiety was measured by the Beck Anxiety Inventory (BAI) questionnaire. BAI has passed the reliability and validity test based on Cronbach's alpha assessment with a value of 0.94.7 Sleep quality was assessed by the Pittsburgh Sleep Quality Index (PSQI) questionnaire. This instrument has been tested for reliability and validity based on Cronbach's alpha assessment with a value of $0.83{ }^{8}$

The data obtained were analyzed with the help of statistical programs on the Statistical Package for Social Science (SPSS) version 21. A p-value of $<0.05$ was considered statistically significant.

\section{Results}

There were 48 subjects enrolled in this study. Most of the study subjects were male (85.4\%). The subjects of this study were mostly using addictive substances (52.1\%) in the form of cigarettes and coffee (Table 1). Table 2 shows the results of the BAI and PSQI score. As displayed, most of the subjects were not anxious (66.7\%) and have poor quality of sleep (87.5).

Table 1. Subjects characteristics

\begin{tabular}{lc}
\hline \multicolumn{1}{c}{ Variables } & Value \\
\hline Age (years), mean \pm SD & $30.4 \pm 3.4$ \\
Gender, $\mathrm{n}(\%)$ & $41(85.4)$ \\
$\quad$ Man & $7(14.6)$ \\
$\quad$ Woman & \\
Marital status, $\mathrm{n}(\%)$ & $28(58.3)$ \\
$\quad$ Married & $20(41.7)$ \\
Not Married & $29(60.4)$ \\
Semester, $\mathrm{n}(\%)$ & $19(39.6)$ \\
$1-4$ & $25(52.1)$ \\
$5-12$ & $23(47.9)$ \\
Addictive substances, $\mathrm{n}(\%)$ & \\
$\quad$ Yes & \\
$\quad$ No &
\end{tabular}

Table 2. Results of assessment of anxiety and sleep quality

\begin{tabular}{lc}
\hline \multicolumn{1}{c}{ Variables } & Value \\
\hline BAI, n(\%) & $16(33.3)$ \\
Anxiety & $32(66.7)$ \\
Not worried & \\
& \\
PSQI, n(\%) & $42(87.5)$ \\
Bad & $6(12.5)$ \\
Good & \\
\hline BAI: Beck Anxiety Inventory; PSQI: Pittsburgh Sleep Quality Index
\end{tabular}

Table 3. The distribution of sleep quality based on anxiety

\begin{tabular}{|c|c|c|c|c|c|c|c|c|}
\hline & & \multicolumn{4}{|c|}{ Sleep Quality } & \multirow[t]{3}{*}{ PR } & \multirow[t]{3}{*}{$95 \% \mathrm{CI}$} & \multirow[t]{3}{*}{$p$} \\
\hline & & \multicolumn{2}{|c|}{$\mathrm{Bad}$} & \multicolumn{2}{|c|}{ Good } & & & \\
\hline & & $\mathrm{N}$ & $\%$ & $\mathrm{~N}$ & $\%$ & & & \\
\hline \multirow[t]{2}{*}{ Anxiety } & Present & 6 & 37.5 & 10 & 62.5 & 3.0 & $0.9-9.1$ & 0.044 \\
\hline & Absent & 4 & 12.5 & 28 & 87.5 & & & \\
\hline
\end{tabular}

In this study, there was a difference in the proportion between anxiety and non-anxiety states between subjects with poor sleep quality and good sleep quality $(\mathrm{p}=0.044)$. The subjects who are in anxious state has triple the chance of experiencing poor sleep quality compared to those who are not anxious (Table 3 ).

\section{Discussion}

From this study it was found that the average age of the subjects was $30.4 \pm 3.4$ years. Research by Tomlinson et al., the average age of a surgical resident is 30 years, and dominated also by male and married status. This study was also dominated by male sex with a greater percentage (85.4\%) but dominated by married people (58.3\%).

About half of the subjects consume a reasonable amount of coffee or cigarettes. They consumed an average of two cups of coffee a day and smoked 3-6 cigarettes a day. By statistical analysis, these addictive substances did not affect anxiety about sleep quality. None of the subejects take sleeping pills, anti-anxiety drugs, anti-depressants medications, or narcotics.

This study shows anxiety in General Surgery residents was $33.3 \%$. This is in accordance with research by Dave et al. in their research on the prevalence of depression, anxiety and stress in resident doctors in teaching hospitals in India, where the prevalence of depression in resident doctors was (27.1\%), anxiety (36.58\%), and stress $(24.24 \%)$. They also mentioned that variables such as junior semesters, long working hours, no job satisfaction, no hobbies, and living in a boarding house gave significantly high levels of depression, anxiety, and stress. These variables were not measured in our research

Most subjects reported poor sleep quality by PSQI (87.5\%). This is similar to a cross-sectional study conducted in 2017 about sleep quality in resident doctors. More than a third of resident doctors experience daytime sleepiness based on poor Epworth Sleepiness Scale (ESS) scores. This significantly affects aspects of their quality of life, including physical health, body aches, and general health. It is said that health promotion is needed regarding sleep and quality of life for resident doctors. ${ }^{13}$ 
Al-Saif in his research on the prevalence and risk factors of poor sleep quality in 1205 resident doctors in Saudi Arabia showed that $86.3 \%$ of the subjecs reported poor sleep quality. The on-call schedule and night duty are the main risk factors for poor sleep quality in his research and it is recommended that working hours be limited to 80 hours a week. ${ }^{14}$ Some residents with normal sleep at the beginning of the residency end up having severe sleep disturbance, some even more severe than those who already have sleep disorders before. Recognition and management of fatigue are very important. ${ }^{15-19}$

This research shows that there is a positive relationship between anxiety and sleep quality. This is similar to previous research on the relationship between anxiety levels and sleep quality in 278 medical students at the undergraduate, graduate, and doctoral levels. They reported that people with high stress levels had various levels of psychological suffering such as anxiety and depression. The results of the study showed that $73 \%$ of students experienced moderate anxiety and severe anxiety, and $46.4 \%$ had a PSQI score of $\geq 5$ which reflects a poor sleep quality $(\mathrm{p}<0.001) .{ }^{16}$

A study that assessed the relationship between anxiety, sleep quality, the branch of medicine studied and hours of work, the number of tasks and daily habits of resident doctors in a hospital in Turkey showed that surgical resident doctors have anxiety levels related to sleep quality significantly poor $(\mathrm{p}=0.007){ }^{20}$

Al Ajmi's study 19 of all 71 Saudi Joint Program of Family Medicine resident doctors assessed the quality of their sleep compared to doctors in primary care. The study showed that residents in the earlier semester (first and second years) had a poor sleep quality compared to the last semester (third and fourth years). This is explained by more rotations and on-call tasks at this level. The study also showed that marital status significantly influences sleep quality, where married doctors have worse sleep quality than unmarried. However, this is not the case in the author's study, where after being controlled by analysis, it was found that marital status did not affect sleep quality.

Sargent et al. ${ }^{18}$ in his research on anxiety and coping in 21 orthopedic surgery residents found that high levels of emotional exhaustion in residents were associated with anxiety about clinical competence $(\mathrm{p}<0.02)$, increased conflict between work and home life $(\mathrm{p}<0.001)$, relationships with senior residents $(\mathrm{p}<0.07)$, and perceptions of their work or education $(\mathrm{p}<0.002)$.

There is always an increased risk of disruption of sleep quality to mental and physical morbidity due to working on a tight schedule and changes in sleep wake cycle patterns. Poor sleep quality can cause various neurophysiological and psychological imbalances such as decreased alertness and mood changes that can affect individual performance.

The research has several limitations. The first limitation is that this study was a cross-sectional design in which data collection is carried out once without follow-up. Secondly, subjects may tend to give more "acceptable" answers than "honest" answers to the questionnaire. Third, knowing the many factors that can affect anxiety and the quality of sleep, there are always a number of other biases that Published by: IndoScholar Publishing Services (www.indoscholar.com) cannot be controlled. Last, the writer used BAI as an anxiety questionnaire and PSQI as a sleep quality questionnaire. The use of other questionnaires to assess anxiety and sleep quality in other studies can be a challenging comparison.

\section{Conclusion}

The prevalence of anxiety in the residents of General Surgery of Udayana University was $33.3 \%$. The sleep quality was mostly poor at $87.5 \%$. There is a significant relationship between anxiety and sleep quality amonst the study subjects.

\section{Acknowledgement}

The authors report no conflict of interests.

\section{Reference}

1. J. D. Stein, E. Hollander and O. B. Rothbaum, "Anxious Traits and Temperaments," in Textbook of Anxiety Disorder, 2nd ed., New York, American Psychiatric Publishing, 2009, pp. 73-147.

2. H. Elvira, "Gangguan Cemas," in Buku Ajar Psikiatri, Jakarta, Badan Penerbit FKUI, 2014, pp. 229-231.

3. H. Ritchie and M. Roser, "Our World in Data," 2018. [Online]. Available: https://ourworldindata.org/mental-health. [Accessed 31 May 2019]

4. S. Chokroverty, "Overview of Sleep and Sleep Disorder," Indian J Med Res, vol. 131, pp. 126-140, 2010.

5. W. Pigeon, K. Heffner, P. Duberstein, K. Fiscella, J. Moynihan and B. Chapman, "Elevated Sleep Disturbance Among Blacks in an Urban Family Medicine pRactice.," J Am Board Fam Med, vol. 24, pp. 161-8, 2011.

6. S. Campbell and D. Delva, "Physician do not heal thyself, Survey of personal health practices among medical residents," Canadian Family Physician, pp. 1121-1127, 2003.

7. M. D. Iqbal, "Hubungan Aktivitas Fisik dengan Kualitas Tidur Mahasiswa Perantau di Yogyakarta," Universitas Negeri Yogyakarta, Yogyakarta, 2017.

8. S. Kunarni, "Pengaruh meditasi dzikir untuk menurunkan kecemasan pada narapidana wanita menjelang masa bebas," Walisongo, Semarang, 2014.

9. J. Jeekel, "Crucial Times for General Surgery," Ann Surg, vol. 230, no. 6, p. 739, 1999.

10. C. Tomlinson, J. LaBossiere, K. Rommens and D. W. Birch, "The Canadian general surgery resident: defining current challenges for surgical leadership," Can J Surg, vol. 55, no. 4 Suppl 2, pp. S184-S190, 2012

11. S. Dave, M. Parikh, G. Vankar and V. S. Kartik, "Depression, anxiety, and stress among resident doctors of a teaching hospital," Indian Journal of Social Psychiatry, vol. 34, no. 2, pp. 163-171, 2018

12. J. González-Cabrera, M. Fernández-Prada, C. Iribar, R. Molina-Ruano, M. Salinero-Bachiller and J. M. Peinado, "Acute Stress and Anxiety in Medical Residents on the Emergency Department Duty," Int J Environ Res Public Health, vol. 15, no. 3, 
13. Y. Z. Alami, B. T. Ghanim and S. H. Zyoud, "Epworth sleepiness scale in medical residents: quality of sleep and its relationship to quality of life," J Occup Med Toxicol, vol. 13, no. 21, 2018.

14. H. I. AlSaif, "Prevalence of and risk factors for poor sleep quality among residents in training in KSA," Journal of Taibah University Medical Sciences, vol. 14, no. 1, pp. 52-59, 2019.

15. S. McGreevey, "Not Enough Sleep," 2018. [Online]. Available: https://hms.harvard.edu/news/not-enough-sleep. [Accessed 27 June 2019].

16. M. Kalyani, N. Jamshidi, J. Salami and E. Pourjam, "Investigation of the Relationship between Psychological Variables anad Sleep Quality in STudents of Medical Sciences," Depression Research and Treatment, vol. 2017, 2017.

17. A. D. Esen, G. Mercan, E. Kacar and D. Toprak, "Sleep Quality and Related Factors in Medical Resident," Turkish Journal of
Family Medicine and Primary Care, vol. 11, no. 4, pp. 271-277, 2017.

18. J. Loria-Castellasnos, J. M. Rocha-Luna and G. Marquez-Avilla, "Sleep pattern and perception of sleep quality among medical residents and the relation to anxiety and depression," Emergencias, vol. 22, pp. 33-39, 2010.

19. M. Al Ajmi, "Sleep quality among residents of Saudi Board of Family Medicine compared to service physicians in primary care centers," International Journal of Medical Science and Public Health, vol. 4, no. 7, pp. 982-986, 2015.

20. M. Sargent, W. Sotile, M. O. Sotile, H. Rubash and R. L. Barrack, "Stress and Coping Among Orthopaedic Surgery Residents and Faculty," The Journal of Bone and Joint Surgery, Vols. 86A, no. 7, pp. 1578-1586, 2004. 